\title{
Prevalence of physical inactivity and associated cardiometabolic risk factors: A cross-sectional study
}

\author{
Drs. Juan Salazar ${ }^{1}$, Wheeler Torres ${ }^{1}$, Luis Olivar ${ }^{1}$, Valeria Gallo ${ }^{1}$, Eliana Luzardo ${ }^{1}$, Victor Lameda \\ $\mathrm{Bsc}^{1}$, Paola Ramírez Bsc${ }^{1}$, Néstor Galbán $\mathrm{Bsc}^{1}$, Milagros Rojas ${ }^{1}$, Clímaco Cano Ponce $\mathrm{PhD}^{1}$, \\ Roberto Añez ${ }^{2}$, Maricarmen Chacín MSc ${ }^{3}$,Valmore Bermúdez MPH, MSc, $\mathrm{PhD}^{3}$
}

\begin{abstract}
SUMMARY
Background: Physical inactivity represents a public health problem associated with non-communicable diseases. This study aimed to determine both general and domain-specific prevalence of physical inactivity as well as its association with cardiometabolic factors. Methods: A cross-sectional study was performed, including 2230 adult individuals from both sexes from Maracaibo city. Physical activity was assessed by the long-form of the International Physical Activity Questionnaire. A value $<600$ METminutes/week was defined as a cut-off for physical inactivity. A multivariant logistic regression analysis was performed for each IPAQ domain. Results: The highest prevalence of physical inactivity was in the transportation (80.3\%), followed by work (79.9\%), leisure (76.8\%), and household (47.9\%) domain. In the first three domains, physical inactivity was more frequent in women, and the majority of subjects were inactive in three orfour domains simultaneously. Being a woman, being $>30$ years old, Asian-Middle Eastern
\end{abstract}

DOI: https://doi.org/10.47307/GMC.2020.128.3.14

Juan Salazar1 juanjsv18@hotmail.com ORCID No. 0000-0003-4211-528X

Wheeler Torres ${ }^{1}$ wheelertorres10@ hotmail.com ORCID No. 0000-0002-7068-0190

Luis Olivar ${ }^{1}$ olivarlc@ hotmail.com

ORCID No. 0000-0002-9325-6376

Valeria Gallovvaleriavgallo@gmail.com

ORCID No.0000-0002-2988-7309

Eliana Luzardo ${ }^{1}$ elianaluzardo@gmail.com

ORCID No. 0000-0002-5639-7639

Victor Lameda ${ }^{1}$ viclam95@gmail.com

ORCID No. 0000-0003-4769-1497

Paola Ramirez ${ }^{1}$ paolapaternina1994@gmail.com

ORCID No. 0000-0002-5986-0246

Nestor Galban'1 nestorag17@gmail.com

ORCID No. 0000-0003-0765-2290

Milagros Rojas ${ }^{1}$ migarocafi@gmail.com

ORCID No. 0000-0003-2764-8846 ethnicity, and former smoker status were variables associated with leisure-time physical inactivity. In the transportation domain, associated variables were being a woman, being overweight, and being obese. In the work domain, being a woman, age $>50$ years old, high school studies, employed work status, and type 2 diabetes mellitus were the associated variables. Lastly, in the household domain, an association was seen with males, II-IV socioeconomic status, and employed work status. Conclusion: There is a high prevalence of physical inactivity in residents of Maracaibo city, which is why the implementation of plans promoting physical activity is necessary.

Key words: Sedentary, physical inactivity, riskfactor, leisure time, transportation.

\section{RESUMEN}

Introducción: La inactividad física es un problema de salud pública asociado a enfermedades crónicas no transmisibles. Determinar la prevalencia general

\footnotetext{
Climaco Cano ${ }^{1}$ Ponce climacoc@hotmail.com ORCID No. 0000-0002-8103-3714

Roberto Añez ${ }^{2}$ Roberto_anez89@hotmail.com ORCID No.0000-0001-6363-2767

Maricarmen Chacín ${ }^{3}$ m.chacin@unisimonbolivar.edu.co ORCID No.0000-0002-5208-891X

Valmore Bermudez ${ }^{3}$ valmore@gmail.com ORCID No.0000-0003-1880-8887

${ }^{1}$ Endocrine and Metabolic Diseases Research Center. School of Medicine. University of Zulia. Maracaibo, Venezuela. ${ }^{2}$ Departamento de Endocrinología y Nutrición. Hospital General Universitario Gregorio Marañón, Madrid, España ${ }^{3}$ Universidad Simón Bolívar. Facultad de Ciencias de la Salud. Barranquilla, Colombia.

*Corresponding Author: Juan Salazar, MD. The University of Zulia, Endocrine and Metabolic Diseases Research Center, 20th Avenue, Maracaibo 4004, Venezuela. Telephone/Fax Number: 58-261-7597279. E-mail: juanjsv18@ hotmail.com
} 
y por esferas de inactividad física, y su asociación con factores cardiometabólicos. Métodos: Estudio transversal que incluyó 230 individuos adultos de ambos sexos de la ciudad de Maracaibo. Para la evaluación de la actividad física se aplicó la versión larga del Cuestionario internacional de actividad física, definiéndose la inactividad física como $<600$ MET-minutos/semana, se realizó un análisis de regresión logística multivariante para cada dominio. Resultados: La mayor prevalenciade inactividadfísica fue en la esfera de transporte (80,3\%), seguida de la esfera de trabajo (79,9\%), ocio $(76,8 \%)$ y hogar (47,9\%). Enlas 3 primeras esferas la inactividadfísica fue más frecuente en mujeres y la mayoría de sujetos fueron inactivos en 3 o 4 esferas simultáneamente. Las variables asociadas con inactividad física en ocio fueron el sexo femenino, edad $>30$ años, grupo étnico arábigo-asiático y estatus de exfumador; en la esfera transporte fueron el sexofemenino, sobrepeso y obesidad; en la esfera trabajo fueron el sexofemenino, edad $\geq 50$ años, estatus educativo de secundaria, condición laboral de empleado y diabetes mellitus tipo 2; en la esfera hogar fueron el sexo masculino, estrato socioeconómico II-IV y la condición laboral de empleado. Conclusión: Existe una alta prevalencia de inactividad física en los habitantes de la ciudad de Maracaibo, por lo que es necesaria la promoción del ejercicio.

Palabras clave: Sedentarismo, inactividad física, factor de riesgo, actividades de ocio, transporte.

\section{INTRODUCTION}

Cardiovascular disease (CVD) is the most common and one of the most preventable causes of death in the world. Rapid changes in lifestyle and environmental drives to increased exposure to several well-studied risk factors (modifiable or non modifiable) that increase the burden CVD. Regarding modifiable factors, physical activity has an essential preventive role in the development of various pathologies (1) including vasculopathic diseases such as coronary artery disease, stroke, type 2 diabetes, and obesity. Additionally, increased physical activity has been proposed as a therapy to improve musculoskeletal health; however, there are conflicting reports about physical activity potentially leading to degenerative musculoskeletal disease, especially osteoarthritis (OA. There has been a history of inconsistencies regarding the terminology used throughout the years. In 2012, the term 'physical inactivity' was described by the Sedentary Behavior Research Network (SBRN) as performing insufficient amounts of physical activity, which implied not meeting specified thresholds suggested in official guidelines (2).

The World Health Organization recommends that adults aged 18-64 engage in at least 150 minutes of moderate to vigorous-intensity aerobic activity per week. At the same time, muscle-strengthening activity is recommended twice a week to promote the health benefits of being active (3). Based on these values, physical inactivity is one of the biggest public health problems of the 21 st century (4), with approximately one-third of adults worldwide being inactive and a higher physical inactivity prevalence among women and older adults (5) conducted between 2002 and 2004, which investigated the prevalence of physical inactivity in 76 countries, and comprised almost 300000 individuals aged 15 years or older. Each study used the International Physical Activity Questionnaire to assess physical inactivity. The level of development of each country was analyzed by the Human Development Index (HDI. Furthermore, it has been determined that physical inactivity is responsible for an estimated 5 million deaths worldwide (6), and further evidence shows that physical inactivity is also determinant for health costs, representing $3.7 \%$ of the overall health care costs in Canada. Besides, in China, more than $15 \%$ of both medical and non-medical annual costs are attributable to physical inactivity (7).

According to preliminary analysis in the city of Maracaibo performed our team, current levels of physical activity are influenced by insufficient participation in physical activity during leisure time and an increase in sedentary behavior during work and household activities (8). Sedentarism refers to very low energy expenditure, where sitting or lying is the dominant mode of posture. Reports in Venezuela that describe patterns of physical activity are scarce or limited to specific groups population, especially children and adolescents or young adults as well as university students $(9,10)$, this makes it impossible to extrapolate the results to large cities. Therefore, this study aimed to determine the prevalence of overall and domain-specific physical inactivity and its association with cardiometabolic factors. 


\section{MATERIALS AND METHODS}

\section{Study design and sample selection}

This report is a sub-study of the Maracaibo City Metabolic Syndrome Prevalence Study, a cross-sectional and randomized study aimed to identify the prevalence of metabolic syndrome (MS) and cardiovascular risk factors in the adult population of Maracaibo city. The sample (2 230 individuals) was calculated based on estimations of the city's population by the National Institute of Statistics 2010's census (1 428043 inhabitants). The sampling process was carried out during 2007-2010, further details have been previously published elsewhere (11).

\section{Ethical considerations}

All participants signed a written consent before undergoing the physical examination and blood sample collection. This project was approved by the Ethics Committee of the Endocrine and Metabolic Diseases Research Center of The University of Zulia, Maracaibo, Venezuela.

\section{Subjects' evaluation}

All participants were subject to a complete physical examination, physical evaluation, and anthropometric measurements. The information that was obtained from anamnesis and included socioeconomic data, education and working status, ethnicity, and smoking, and drinking habit. Subjects were asked about the smoking habits presence and its duration, which were categorized as a) Current smoker, any subject who had smoked more than 100 cigarettes in his/her lifetime, is currently smoking, or less than one year had passed after he/she quit smoking; b) Former Smoker: any subject who has quit smoking for more than one year; c) Non-smoker, any subject who has never smoked or had smoked less than 100 cigarettes in his/her lifetime as stated by the National Health Interview Survey (NHIS) adult tobacco use questions (12). Assessment of blood pressure was done using a calibrated mercury sphygmomanometer, with patients previously rested (during at least 15 minutes) in a sitting position with both feet touching the floor; the arm was positioned at the heart level, and the proper sized cuff was used for the procedure. The Seventh Report of the Joint National Committee on Prevention, Detection, Evaluation, and Treatment of High Blood Pressure (JNC 7) criteria on blood pressure were used to classify this variable as normal BP $<120 / 80 \mathrm{mmHg}$, prehypertension in those with systolic blood pressure (SBP) 120-139 $\mathrm{mmHg}$ and/or diastolic blood pressure (PAD) between $80-89 \mathrm{mmHg}$, and hypertension when BP is $\geq 140 / 90 \mathrm{mmHg}$ (13). Anthropometric measures were taken using a height rod, previously calibrated and placed on a flat surface. Weight was measured using a digital weighing scale (Tanita,TBF-310 GS Body Composition Analyzer, Tokyo - Japan), with the patient using light clothes and shoeless. Body mass index (BMI) was calculated applying the Quetelet's equation [Weight/Height2], and the participants were classified according to $\mathrm{WHO}$ classification in Normal Weight $\left(<25 \mathrm{~kg} / \mathrm{m}^{2}\right)$, Overweight (25.0-29.9 kg/m2), Obese ( $\geq 30.0$ $\mathrm{kg} / \mathrm{m}^{2}$ ) (14). Waist circumference (WC) was measured using calibrated measuring tapes by the anatomical landmarks proposed by the USA National Institutes of Health protocol (15).

\section{Physical activity Aasessment}

The International Physical Activity Questionnaire-Long Form (IPAQ-LF), which has been validated in over 12 other countries was used for the evaluation of PA (16). Its design allows for the assessment of PA in four domains: Work, transportation, household, and leisure activity. It includes items corresponding to the frequency and duration of walks; and the frequency and duration of vigorous or high-intensity activities of at least 10 minutes of duration, in the 7 days before application. Minutes/week of walking and vigorous activities was converted to metabolic equivalents (MET) to estimate energy exertion. Data were calculated according to the average MET result for each activity, and from the sum of these, four continuous scores were formulated, defined as follows (17):

- Walking MET-minutes/week= $3.3 \times$ minutes walked $\mathrm{x}$ days walked. 
- Moderate MET-minutes/week=4.0 x minutes of moderate-intensity activities $\mathrm{x}$ days of moderate-intensity activities.

- Vigorous MET-minutes/week $=8.0 \times$ minutes of vigorous activity $\mathrm{x}$ days of vigorous activity.

- Total Physical Activity MET-minutes/week= Walking + Moderate + Vigorous METminutes/week.

A cut-off point of $<600$ MET-minutes / week for domains was used to define the individuals with physical inactivity (18).

\section{Laboratory analysis}

Overnight fasting determination of glucose, total cholesterol, triacylglycerides (TAG), and HDL-C was performed with an automated analyzer (Human Gesellschaftfür Biochemica und DiagnosticambH, Germany). The intra-assay variation coefficients for total cholesterol, TAG, and HDL-C were $3 \%, 5 \%$, and $5 \%$, respectively. LDL-C and VLDL-C levels were calculated, applying Friedewald's formula when TAG levels were $<400 \mathrm{mg} / \mathrm{Dl}$ (19). When TAG levels were above this cut-off, LDL-C serum concentration was measured through lipoprotein electrophoresis and densitometry with BioRad GS-800 (BioRad).

\section{Definitions}

Fasting glycaemic status was classified according to the ADA 2019 criteria in normal fasting blood glucose (Basal glucose $\geq 60 \mathrm{mg}$ / $\mathrm{dL}$ and $<100 \mathrm{mg} / \mathrm{dL}-)$, impaired fasting glucose (fasting blood glucose between 100-125 mg/dL), and type 2 diabetes mellitus (T2DM) ( $\geq 126 \mathrm{mg} /$ dL) (20). Main dyslipidemias were high TAG levels $(\geq 150 \mathrm{mg} / \mathrm{dL})$ and low HDL-C ( $<40 \mathrm{mg}$ / $\mathrm{dL}$ for men or $<50 \mathrm{mg} / \mathrm{dL}$ for women). Elevated WC cut-off was set at $\geq 80 \mathrm{~cm}$ in females or $\geq 90$ $\mathrm{cm}$ in males (21)which occur together more often than by chance alone, have become known as the metabolic syndrome. The risk factors include raised blood pressure, dyslipidemia (raised triglycerides and lowered high-density lipoprotein cholesterol.

\section{Statistical analysis}

Qualitative variables were expressed as absolute and relative frequencies, evaluating association through Pearson's Chi-squared $\left(\chi^{2}\right)$ test. Domain-specific multiple logistic regression models were constructed to estimate odds ratios (CI95\%) for leisure, transport, work, and household physical inactivity, adjusted for sex, age groups, ethnic groups, socioeconomic, educational and work status, smoking, and alcohol habit, elevated WC, high TAG, low HDL, glycemic status, BPand BMI classification. SPSS v.19 software (SPSS IBM Chicago, IL) was used to build and audit the database, and to perform all statistical analyses in this study. The results were considered statistically significant when $\mathrm{P}<0.05$.

\section{RESULTS}

\section{General characteristics of the sample}

A total of 2230 subjects were included in the study, of which $52.6 \%(n=1,172)$ were female. The mean population age was $39.3 \pm 15.4$. Sociodemographic and clinical variables' behavior are shown in Table 1.

\section{Physical inactivity according to IPAQ domains}

In Table 2, the prevalence of physical inactivity, according to the IPAQ domains, is presented. Women had a higher frequency of physical inactivity when compared with men in the work (women: $84.1 \%$ vs men: $75.2 \%$; $\chi^{2}=27.395, \mathrm{P}<0.001$ ), transportation (women: 84.0 \% vs men: $\left.76.1 \% ; \boldsymbol{\chi}^{2}=22.231, \mathrm{P}<0.001\right)$, and leisure time domains (women: $85.6 \%$ vs men: $\left.67.1 \% ; \chi^{2}=106.542, \mathrm{P}<0.001\right)$. The opposite was found in the household domain (women: $36.9 \%$ vs men: $\left.60 \%, \boldsymbol{\chi}^{2}=118.623, \mathrm{P}<0.001\right)$. The majority of individuals were inactive in 3 or 4 IPAQ domains (3 domains: $42.3 \%$, and 4 domains: $26.6 \%$ ), glycemic status was the only variable that showed an association with the number of physical inactivity domains.

Factors associated with physical inactivity by domains

- Leisure time sphere: Men(OR: 0.33; CI95.\%: 
0.26-0.43; $\mathrm{P}<0.001)$, subjects of Asian-Middle Eastern origin (OR: 0.16; CI95 \%: 0.05-0.53; $\mathrm{P}=0.002)$ and former smokers (OR: 0.61; CI95.\%: 0.41-0.90; $\mathrm{P}=0.014$ ) showed a lower risk of physical inactivity compared to women, subjects of mixed ethnicity, and smokers, respectively. Regarding age groups, older age was associated with the presence of physical inactivity (Figure 1).

Table 1

General features of the sample from Maracaibo City

\begin{tabular}{|c|c|c|c|c|c|c|}
\hline & \multicolumn{2}{|c|}{ Women } & \multicolumn{2}{|c|}{ Men } & \multicolumn{2}{|c|}{ Total } \\
\hline & $\mathrm{n}$ & $\%$ & $\mathrm{n}$ & $\%$ & $\mathrm{n}$ & $\%$ \\
\hline \multicolumn{7}{|l|}{ Age groups (years) } \\
\hline$<30$ & 349 & 29.8 & 413 & 39.0 & 762 & 34.2 \\
\hline $30-49$ & 467 & 39.8 & 391 & 37.0 & 858 & 38.5 \\
\hline$\geq 50$ & 356 & 30.4 & 254 & 24.0 & 610 & 27.4 \\
\hline \multicolumn{7}{|l|}{ Socioeconomic Status } \\
\hline Stratum V: Extreme poverty & 66 & 5.6 & 39 & 3.7 & 105 & 4.7 \\
\hline Stratum IV: Working class & 449 & 38.3 & 349 & 33.0 & 798 & 35.8 \\
\hline Stratum III: Middle class & 432 & 36.9 & 446 & 42.2 & 878 & 39.4 \\
\hline Stratum II: Upper-middle class & 208 & 17.7 & 205 & 19.4 & 413 & 18.5 \\
\hline Stratum I: Upper class & 17 & 1.5 & 19 & 1.8 & 36 & 1.6 \\
\hline \multicolumn{7}{|l|}{ Educational status } \\
\hline College/university & 382 & 32.6 & 402 & 38.0 & 784 & 35.2 \\
\hline High school & 517 & 44.1 & 524 & 49.5 & 1041 & 46.7 \\
\hline Primary school & 240 & 20.5 & 113 & 10.7 & 353 & 15.8 \\
\hline Illiterate & 33 & 2.8 & 19 & 1.8 & 52 & 2.3 \\
\hline \multicolumn{7}{|l|}{ Ethnicity } \\
\hline Asian- Middle Eastern & 13 & 1.1 & 1 & 0.1 & 14 & 0.6 \\
\hline Amerindians & 62 & 5.3 & 44 & 4.2 & 106 & 4.8 \\
\hline Afro-Venezuelans & 30 & 2.6 & 36 & 3.4 & 66 & 3.0 \\
\hline White Hispanic & 191 & 16.3 & 161 & 15.2 & 352 & 15.8 \\
\hline Mixed & 876 & 74.7 & 816 & 77.1 & 1692 & 75.9 \\
\hline \multicolumn{7}{|l|}{ Work Status } \\
\hline Unemployed & 642 & 54.8 & 291 & 27.5 & 933 & 41.8 \\
\hline Employed & 530 & 45.2 & 767 & 72.5 & 1297 & 58.2 \\
\hline \multicolumn{7}{|l|}{ Smoking } \\
\hline Current smokers & 119 & 10.2 & 192 & 18.1 & 311 & 13.9 \\
\hline Non-smokers & 878 & 74.9 & 667 & 63.0 & 1545 & 69.3 \\
\hline Former smokers & 175 & 14.9 & 199 & 18.8 & 374 & 16.8 \\
\hline \multicolumn{7}{|l|}{ Body mass index (BMI) } \\
\hline \multicolumn{7}{|l|}{ Classification } \\
\hline Normal weight & 420 & 35.8 & 275 & 26.0 & 695 & 31.2 \\
\hline Overweight & 371 & 31.7 & 415 & 39.2 & 786 & 35.2 \\
\hline Obese & 381 & 32.5 & 368 & 34.8 & 749 & 33.6 \\
\hline \multicolumn{7}{|l|}{ Glycemic status } \\
\hline Normoglycemic & 871 & 74.3 & 736 & 69.6 & 1607 & 72.1 \\
\hline Impaired fasting glucose & 202 & 17.2 & 233 & $2 ., 0$ & 435 & 19.5 \\
\hline Type 2 Diabetes Mellitus & 99 & 8.4 & 89 & 8.4 & 188 & 8.4 \\
\hline Total & 1172 & 5.6 & 1058 & 47.4 & 2230 & 100 \\
\hline
\end{tabular}


PREVALENCE OF PHYSICAL INACTIVITY

Table 2

Physical inactivity prevalence and its association by sex according IPAQ domains

\begin{tabular}{|c|c|c|c|c|c|c|c|}
\hline & \multicolumn{2}{|c|}{ Women } & \multicolumn{2}{|c|}{ Men } & \multicolumn{2}{|c|}{ Total } & $\chi 2\left(\mathrm{p}^{*}\right)$ \\
\hline & $\mathbf{n}$ & $\%$ & $\mathbf{n}$ & $\%$ & $\mathbf{n}$ & $\%$ & \\
\hline Workg & & & & & & & $27.395(<0.001)$ \\
\hline Active & 186 & 15.9 & 262 & 24.8 & 448 & 20.1 & \\
\hline Inactive & 986 & 84.1 & 796 & 75.2 & 1782 & 79.9 & \\
\hline Transportation & & & & & & & $22.231(<0.001)$ \\
\hline Active & 187 & 16.0 & 253 & 23.9 & 440 & 19.7 & \\
\hline Inactive & 985 & 84.0 & 805 & 76.1 & 1790 & 80.3 & \\
\hline Household I & & & & & & & $118.623(<0.001)$ \\
\hline Active & 739 & 63.1 & 423 & 40.0 & 1162 & 52.1 & \\
\hline Inactive & 433 & 36.9 & 635 & 60.0 & 1068 & 47.9 & \\
\hline Leisure time I & & & & & & & $106.542(<0.001)$ \\
\hline Active & 169 & 14.4 & 348 & 32.9 & 517 & 23.2 & \\
\hline Inactive & 1003 & 85.6 & 710 & 67.1 & 1713 & 76.8 & \\
\hline
\end{tabular}

\section{LEISURE}

\begin{tabular}{lcc|} 
Sex & OR (IC 95\%)* & $\boldsymbol{p}$ \\
Women & 1 & - \\
Men & $\mathbf{0 . 3 3}(\mathbf{0 . 2 6 - 0 . 4 3 )}$ & $<\mathbf{0 . 0 0 1}$ \\
Age groups (years) & & \\
$<30$ & 1 & - \\
$30-49$ & $\mathbf{1 . 8 5}(\mathbf{1 . 4 1 - 2 . 4 2})$ & $<\mathbf{0 . 0 0 1}$ \\
$\geq 50$ & $\mathbf{1 . 9 3}(\mathbf{1 . 3 8 - 2 . 7 1 )}$ & $<\mathbf{0 . 0 0 1}$ \\
Ethnicity & & \\
Mixed & 1 & - \\
White Hispanic & $1.02(0.75-1.37)$ & 0.895 \\
Afro-Venezuelans & $0.85(0.46-1.56)$ & 0.617 \\
Amerindians & $0.79(0.46-1.36)$ & 0.408 \\
Asian-Middle Eastern & $\mathbf{0 . 1 6 ( \mathbf { 0 . 0 5 } - \mathbf { 0 . 5 3 } )}$ & $\mathbf{0 . 0 0 2}$ \\
Smoking & & \\
Current smokers & 1 & - \\
Non smokers & $0.80(0.58-1.11)$ & 0.192 \\
Former smokers & $\mathbf{0 . 6 1}(\mathbf{0 . 4 1 - 0 . 9 0 )}$ & $\mathbf{0 . 0 1 4}$ \\
BMI Classification & & \\
Normal weight & 1 & \\
Overweight & $0.87(0.64-1.19)$ & 0.402 \\
Obese & $1.21(0.78-1.60)$ & 0.531
\end{tabular}

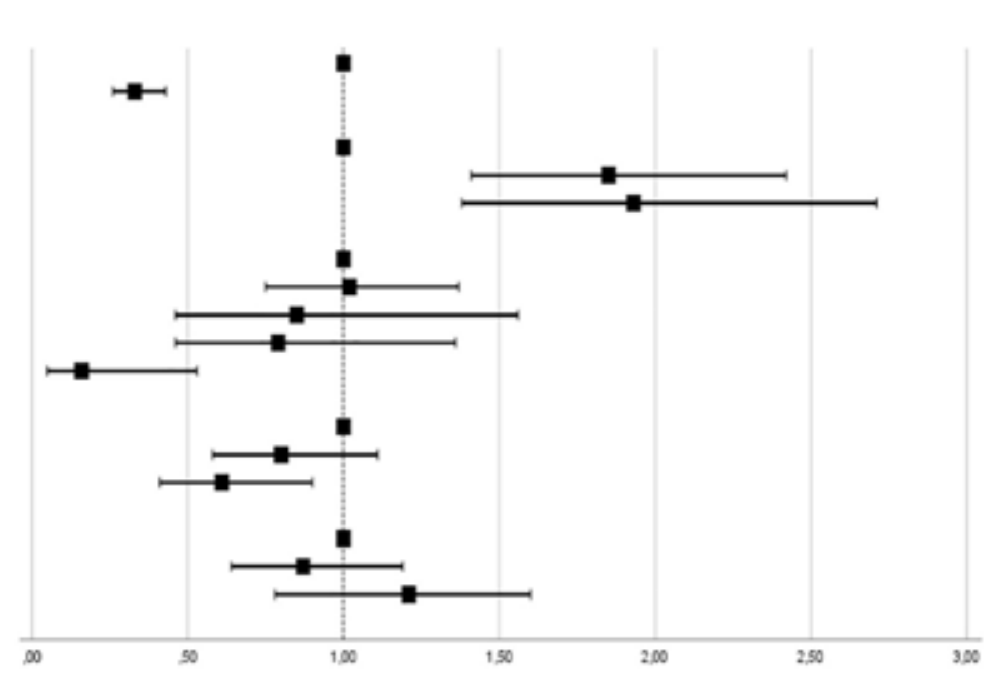

Figure 1. Associated factors with physical inactivity in leisure domain.

* Ajusted model to: sex, age groups, ethnic groups, socioeconomic, educational and work status, smoking and alcohol habit, elevated WC, high TAG, low HDL, glycemic status, BP, and BMI classification.

- Transportation sphere: Similarly, men presented a lower risk of physical inactivity compared to women (OR: 0.54; CI95 \%: 0.42-0.70; $\mathrm{P}<0.001)$. Regarding $\mathrm{BMI}$, obese (OR: 1.53; CI95 \%: 1.08-2.16; $\mathrm{P}=0.016$ ) and overweight individuals (OR: 1.42; CI95\%:
1.94; $\mathrm{P}=0.025$ ) had a higher risk of physical inactivity in this domain (Figure 2).

- Work sphere: Subject who were $\geq 50$ years old (OR: 1.55; CI95 \%: 1.10-2.18; $\mathrm{P}=0.012$ ), with high school education (OR: 5.65; CI95 \%: 1.28-24.97; $\mathrm{P}=0.022)$, and T2DM (OR: 1.68; CI95 \%: 1.03-2.76; $\mathrm{P}=0.038$ ) had 


Sex
Women
Men
Age groups (years)
$<30$
$30-49$
$\geq 50$
Ethnicity
Mixed
White Hispanic
Afro-Venezuelans
Amerindians
Asian-Middle Eastern
Smoking
Current smokers
Non smokers
Former smokers
BMI Classification
Normal weight
Overweight
Obese

\begin{tabular}{cc|} 
OR (IC 95\%)* & $p$ \\
1 & - \\
$\mathbf{0 . 5 4}(\mathbf{0 . 4 2 - 0 , 7 0 )}$ & $<\mathbf{0 . 0 0 1}$ \\
$\mathbf{1}$ & \\
$1.11(0.83-1.48)$ & 0.452 \\
$1.15(0.81-1.61)$ & 0.418 \\
& \\
1 & \\
$2.03(0.61-6.80)$ & 0.246 \\
$2.82(0.81-9.75)$ & 0.101 \\
$1.83(0.48-6.93)$ & 0.372 \\
$1.34(0.38-4.72)$ & 0.648 \\
1 & - \\
$0.87(0.63-1.21)$ & 0.420 \\
$0.88(0.59-1.30)$ & 0.528 \\
1 & \\
1 & - \\
$\mathbf{1 . 4 2}(\mathbf{1 . 0 4 - 1 . 9 4 )}$ & $\mathbf{0 . 0 2 5}$ \\
$\mathbf{1 . 5 3}(\mathbf{1 . 0 8 - 2 . 1 6 )}$ & $\mathbf{0 . 0 1 6}$
\end{tabular}

TRANSPORTATION

Figure 2. Associated factors with physical inactivity in transport domain.

* Ajusted model to: sex, age groups, ethnic groups, socioeconomic, educational and work status, smoking and alcohol habit, elevated WC, high TAG, low HDL, glycemic status, BP, and BMI classification.

a higher risk of physical inactivity compared to those $<30$ years old, with higher studies, and normoglycemic, respectively. While men (OR: 0.74; CI95 \%: 0.58-0.95; $\mathrm{P}=0.021$ ) and employed subjects (OR: 0.48; CI95 \%: $0.37-$ $0.62 ; \mathrm{P}<0.001)$ had a lower risk compared to women and unemployed subjects, respectively (Figure 3).
- Household sphere: Men(OR: 2.51; CI95.\%: 2.05-3.08; $\mathrm{P}<0.001)$, individuals in the IV (OR:3.40; CI95 \%: 1.43-8.07; P=0.005), III (OR:3.35; CI95 \%; 1.92-5.83; P<0.001), or II socioeconomic status (OR: 2.12; CI95 \%: 1.26-3.58; $\mathrm{P}=0.004)$ had a lower risk of physical inactivity. Similar results were

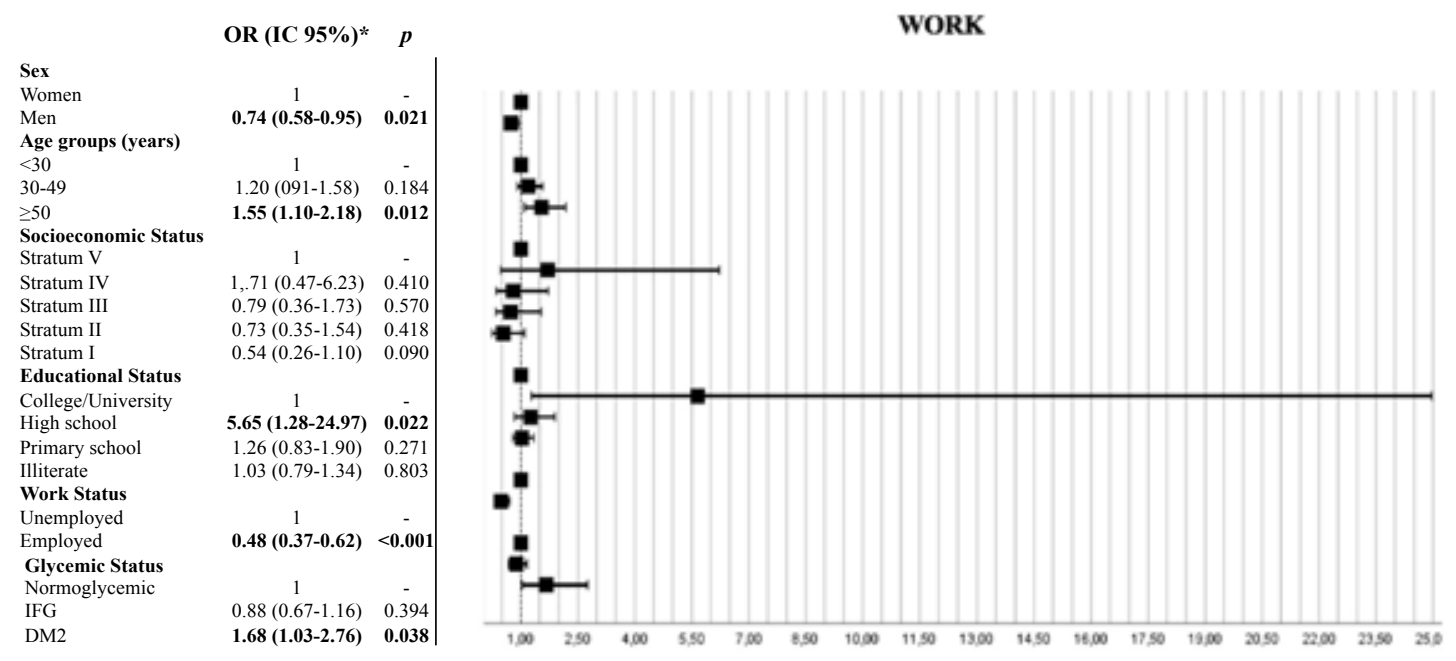

Figure 3. Associated factors with physical inactivity in work domain.

* Ajusted model to: sex, age groups, ethnic groups, socioeconomic, educational and work status, smoking and alcohol habit, elevated WC, high TAG, low HDL, glycemic status, BP, and BMI classification. 
found for those with high school education (OR: 2.20; CI95 \%: 1,14-4.26; P=0.019), and employed individuals (OR:1.23; CI95 \%; 1.01 $1.50 ; \mathrm{P}=0.040$ ) when compared to women, individuals in the I or V socioeconomic status, higher education, and those unemployed, respectively (Figure 4).

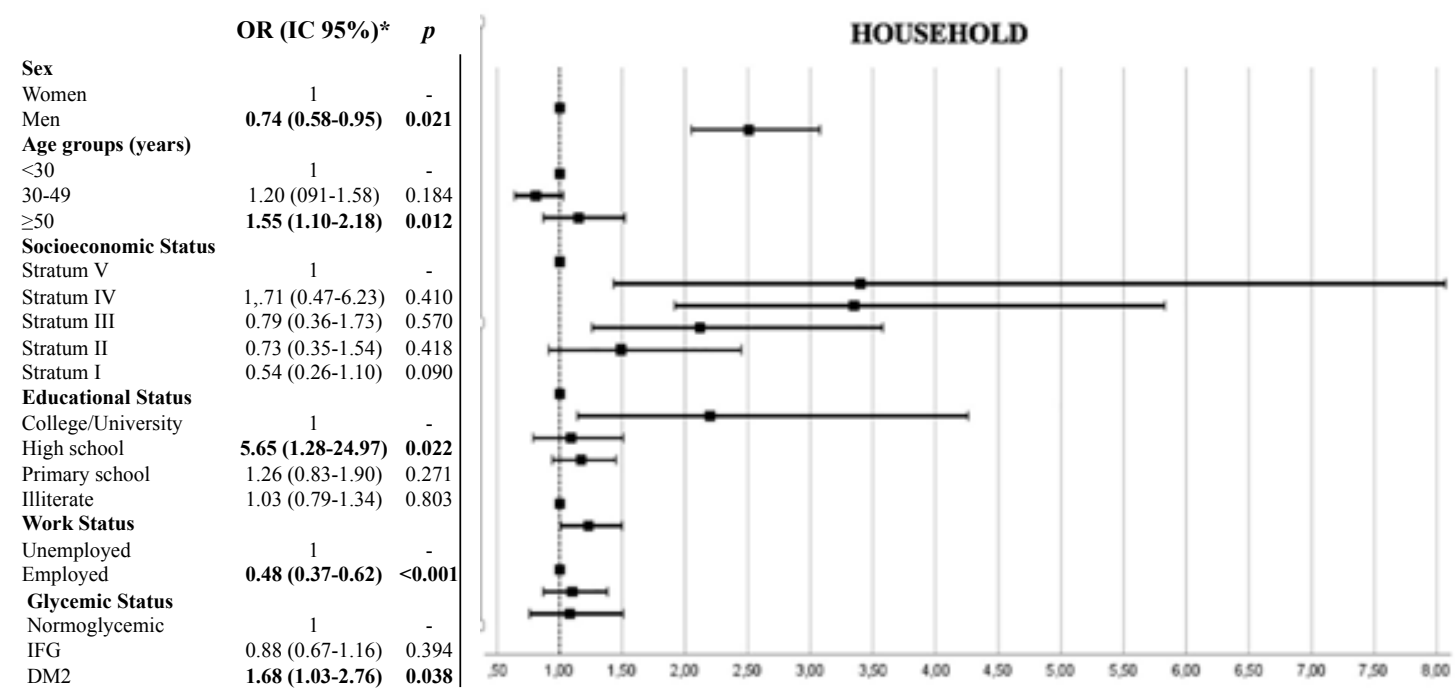

Figure 4. Associated factors with physical inactivity in household domain.

* Ajusted model to: sex, age groups, ethnic groups, socioeconomic, educational and work status, smoking and alcohol habit, elevated WC, high TAG, low HDL, glycemic status, BP, and BMI classification.

Table 3

Associated factors to physical inactivity across all

\section{Factors associated with physical inactivity across all dimensions}

Subjects $\geq 50$ years of age (OR: $1.59 ;$ CI95.\%: 1.71-2.16; $\mathrm{P}=0.003$ ), with T2DM (OR: 1.44; CI95 \%: 1.01-2.03; $\mathrm{P}=0.039)$, and who were part of the IV and III socioeconomic strata had a higher risk being physically inactive across all dimensions (Table 3). domains

Physical inactivity in all domains OR (IC 95\%)* P

\begin{tabular}{lcc}
\multicolumn{3}{c}{ domains } \\
\hline \multicolumn{3}{c}{ Physical inactivity in all domains } \\
& OR (IC 95\%)* & $\mathrm{P}$ \\
Age groups (years) & 1 &. \\
$<30$ & $1.09(0.83-1.42)$ & 0.532 \\
$30-49$ & $1.59(1.71-2.16)$ & 0.003 \\
$\geq 50$ & & \\
Socioeconomic Status & 1 &. \\
Stratum V & $3.84(1.59-9.28)$ & 0.003 \\
Stratum IV & $2.18(1.18-4.02)$ & 0.012 \\
Stratum III & $1.57(0.88-2.81)$ & 0.121 \\
Stratum II & $1.09(0.63-1.89)$ & 0.742 \\
Stratum I & 1 & \\
Glycemic status & $0.88(0.68-1.14)$ & 0.361 \\
Normoglycemic & $1.44(1.01-2.03)$ & 0.039 \\
IFG & &
\end{tabular}

*Ajusted model to: sex, age groups, ethnic groups, socioeconomic, educational and workstatus, smoking and alcohol habit, elevated WC, high TAG, low HDL, glycemic status, BP, and BMI classification. 


\section{DISCUSSION}

During the last years, different reports have shown a high prevalence of cardiometabolic risks in Maracaibo city $(22,23)$. However, factors related to psychobiologic habits and lifestyle have been underreported in Venezuela, a country with scarce large-scale regional or national epidemiologic studies. Therefore, this study aimed to show the prevalence of physical inactivity in Maracaibo city, a risk factor that is frequently underestimated in the clinical evaluation of the adult patient. Besides, this risk factor has been associated with cardiovascular diseases as well as other chronic diseases (24).

There is limited data related to the study of a sedentary lifestyle in low and middle-income countries. This fact is especially actual for Latin America. The South American Physical Activity and Sedentary Behavior Network (SAPASEN) is one of the central studies that have analyzed physical inactivity patterns with data from Argentina, Peru, Ecuador, Brazil, Suriname, and Chile. However, there is no available data from Uruguay, Paraguay, and Venezuela (25). SAPASEN data reported that Latin America has high ranges of total physical inactivity, with frequencies ranging from $60.4 \%$ (Brazil) to $82.9 \%$ (Chile) among men, and between 49.4.\% (Ecuador) and 74.9\% (Chile) in women. Furthermore, differences between countries were also seen when studying domain-specific physical inactivity. The prevalence of physical inactivity during leisure time ranged from 29.2.\% in Argentina to $8.6 \%$ in Peru, while in the transportation sphere Peru showed a prevalence of $69.7 \%$, considerably higher than Ecuador (8.8.\%). Lastly, in the work sphere, Chile showed a prevalence of $60.4 \%$, while Brazil only reported a prevalence of $18.3 \%$.

On the other hand, data from the Latin American Study of Nutrition and Health (ELANS) in which Venezuela is included, showed that the overall prevalence of insufficient physical activity (IPA)in the transport and leisure domains were $69.9 \%$ (95 \% CI: 68.9-70.8) and 72.8 (95.\% CI: 72.0-73.7), respectively. Our country showed the highest IPA of all analyzed countries (transportation: $81 \%$ and leisure: 83,8\%) (26). Besides, López et al, reported a prevalence of sedentary lifestyle of $60.7 \%$ in hypertensive individuals from three Venezuelan cities, without specifying the method used to classify physical activity levels (27). These results, as well as those found in the four IPAQ domains in our study, show the need to develop new policies promoting physical activity in adults. Education about the benefits of regular physical activity is a must as well as the use of strategies that include activities during work, leisure time, and even transportation.

As for the distribution, according to sex, the highest risk of sedentarism observed in women, especially in the leisure time sphere, has been documented in previous reports (28). These differences between men and women can be due to cultural characteristics, time availability, and daily activities performed. This behavior has an impact on psychobiologic habits and, therefore, in their overall health. In this way, policies of physical activity promotion must focus on improving the health of women by promoting spaces, time, and perhaps more importantly, changes in the sociocultural perspectives regarding access and time availability for healthy habits (29).

Regarding physical inactivity during leisure time, this was associated with women and individuals older than 30 years of age, while individuals of Asian and Middle Eastern origin and former smokers had a lower risk compared to other groups. These findings coincide with reports made by Meseguer et al, who performed a cross-sectional study in Madrid finding that women, older adults, and people with lower education levels as well as obese individuals were those with the lowest adherence to recommendations made for physical activity during leisure time ${ }^{\&}(30)$. It is essential to consider the influence that daily household activities can have on-time availability in the case of women. Similarly, these considerations should be made regarding the work activities and time availability of individuals over 30 years.

Meanwhile, physical inactivity in the transportation domain was associated with being female, overweight, and obese. This pattern is similar to what was found by Florindo et al, in a Brazilian population, reporting that women exhibited both insufficient levels of physical activity in this sphere and the highest level of 
overall physical inactivity (31). Active mobility (walking or cycling as a method of transportation) has been established as an important way to perform routine physical activity affordably, and as an initial therapeutic strategy for chronic diseases such as obesity, hypertension, and T2DM (32).

In our work, physical inactivity in the work domain was associated with both T2DM and a high school education level. This finding is the opposite of what was reported by Medina et al, in a prospective study performed in Mexico City. They reported that occupational, physical inactivity increased the risk of hypertension instead of T2DM (33). Meanwhile, Díaz et al, showed that physically inactive individuals had a higher probability of developing diabetes (OR: 2.47; CI: $95 \% ; 1.80-3.38 ; \mathrm{P}<0.001$ ). This fact is likely because exercise increases glucose metabolism as well as insulin sensitivity (34). It is essential to consider in future studies the influence of the type of work and the energy consumption of the worker at risk of suffering this disease.

Finally, in the household domain, men, individuals with high school education, employed, and those in the II and IV social strata showed a higher risk of being inactive. These findings partially coincide with those reported in the aforementioned Brazilian study, in which men, widowed or separated civil status, and high educational level were the factors associated with physical inactivity in the household sphere ${ }^{\&}(31)$. These differences can be attributed to the time availability of these groups in each region. In our case, subjects spend less time at home, possibly due to work reasons, reporting lower METS/min/ week in this sphere.

Overall, there is a high percentage of physical inactivity across all domains. Even in the household sphere, in which the frequency of sedentarism was lowest, almost half of the subjects were inactive. These high frequencies made it necessary to evaluate the profile of factors associated with each domain. This way, the most affected groups can be identified to establish specific intervention measures. The evaluation of global physical activity, meaning, across all domains showed that subjects who are 50 years old or older, T2DM subjects, and those in the
II and IV socioeconomic strata are groups that need to be considered by primary health attention centers. Their physical activity levels need to be evaluated, and plans that allow for a sustained and progressive start of activities that improve their overall health need to be implemented.

Among the limitations of this study, it is vital to mention its cross-sectional design; this makes it impossible to establish causality relationships between the variables. Similarly, the use of a questionnaire as an instrument of physical activity data collection is also a limitation as it is an indirect measurement method, which can be influenced by factors inherent to the subjects. Also, the results reported come from the analysis of a database obtained years ago. Since then, important socioeconomic changes have taken place in Venezuelan society, which means our results might not be a reflection of the current reality of our city. However, there are current projects in our research center that have the goal of evaluating the modifications these epidemiologic patterns have suffered over time.

\section{CONCLUSIONS}

There is a high prevalence of physical inactivity in adult subjects in Maracaibo city, especially in transportation, work, and leisure time domains. Also, there was a significant percentage of physically inactive subjects in several domains simultaneously. The factors associated with physical inactivity vary between spheres, which is why the specific analysis of each domain is recommended to establish more specific preventive strategies for different population groups. Future studies should seek to apply objective methods of physical activity levels, intensity, and time to collect accurate data in this population. Following this recommendation, future studies in Latin American populations might contribute to a deeper understanding of the factors that may influence physical activity and their consequences, to develop strategies to mitigate this problem. 


\section{DISCLOSURE}

The authors have no conflicts of interest to disclose.

\section{REFERENCES}

1. Curtis GL, Chughtai M, Khlopas A, Newman JM, Khan R, Shaffiy S, et al. Impact of Physical Activity in Cardiovascular and Musculoskeletal Health: Can Motion Be Medicine? J Clin Med Res. 2017;9(5):375381. DOI: $10.14740 /$ jocmr3001w.

2. Bames J, Behrens TK, Benden ME, Biddle S, Bond D, Brassard P, et al. Letter to the editor: Standardized use of the terms "sedentary" and "sedentary behaviours". Appl Physiol Nutr Metab Physiol Appl Nutr Metab. 2012;37(3):540-542. DOI: 10.1139/h2012-024.

3. World Health Organization. Global recommendations on physical activity for health. 2010; Available from: http://www.ncbi.nlm.nih.gov/books/NBK305057/.

4. Blair SN. Physical inactivity: The biggest public health problem of the 21 st century. Br J Sports Med. 2009;43(1):1-2. PMID: 19136507.

5. Dumith SC, Hallal PC, Reis RS,Kohl HW. Worldwide prevalence of physical inactivity and its association with human development index in 76 countries. Prev Med. 2011;53(1-2):24-28. DOI: 10.1016/j. ypmed.2011.02.017.

6. PhysicalInactivity Report. 2017.Available from:https:// www.bhf.org.uk/informationsupport/ publications/ statistics/physical-inactivity-report-2017.

7. González K, Fuentes J, Márquez JL. Physical Inactivity, Sedentary Behavior and Chronic Diseases. Korean J Fam Med. 2017;38(3):111-115. DOI: 10.4082/kjfm.2017.38.3.111.

8. Bermúdez VJ, Rojas JJ, Córdova EB, Añez $\mathrm{R}$, Toledo A, Aguirre MA, et al. International physical activity questionnaire overestimation is ameliorated by individual analysis of the scores. Am J Ther. 2013;20(4):448-458. DOI: 10.1097/ MJT.0b013e318235f1f2.

9. Arteaga E, Añez R, Salazar J, Rojas J, Velasco M, Bermúdez V. Prevalencia de sobrepeso y obesidad y su asociación con la actividad física en escolares de la Parroquia Santa Rita Municipio Santa Rita, Estado Zulia. SínDr. Cardiometabólico. 2015;2(3):1-10. http://saber.ucv.ve/ojs/ index.php/rev_sc/article/ view/9281/9102.

10. Pérez B. Salud: entre la actividad física y el sedentarismo. An Venez Nutr. 2014;27(1):119128. https://www.analesdenutricion.org.ve/ ediciones/2014/1/art-17/.
11. Bermúdez V, Marcano RP, Cano C, Arráiz N, Amell A, Cabrera M, et al. The Maracaibo city metabolic syndrome prevalence study: design and scope. Am J Ther. 2010;17(3):288-94. DOI: 10.1097/ MJT.0b013e3181c121bc.

12. NHIS - Adult Tobacco Use Information Homepage. US Department of Health \& Human Services. 2015. Available from: https://www.cdc.gov/nchs/nhis/ tobacco.htm.

13. Chobanian AV, Bakris GL, Black HR, Cushman WC, Green LA, Izzo JL, et al. The Seventh Report of the Joint National Committee on Prevention, Detection, Evaluation, and Treatment of High Blood Pressure: the JNC 7 report. JAMA. 2003;289(19):2560-2572. DOI: $10.1001 /$ jama.289.19.2560.

14. WHO I The world health report 2003 - shaping the future. WHO. World Health Organization; Available from: https://www.who.int/whr/2003/en/.

15. Centers for Disease Control and Prevention. NATIONAL HEALTH AND NUTRITION EXAMINATION SURVEY III Body Measurements (Anthropometry) Westat, Inc.; 1988 [cited 2020 Mar 29]. Available from: https://wwwn.cdc.gov/nchs/data/ nhanes3/manuals/anthro.pdf.

16. Bauman A, Bull F, Chey T, Craig CL, Ainsworth BE, Sallis JF, et al. The International Prevalence Study on Physical Activity: results from 20 countries. Int J Behav Nutr Phys Act. 2009;6(1):21. DOI: 10.1186/14795868-6-21.

17. IPAQ scoring protocol-International Physical Activity Questionnaire. Available from: https://sites.google. com/site/theipaq/scoring-protocol.

18. Crespo-Salgado JJ, Delgado-Martín JL, BlancoIglesias O, Aldecoa-Landesa S. Guía básica de detección del sedentarismo y recomendaciones de actividad física en atención primaria. Aten Primaria. 2015;47(3):175-183. DOI: $10.1016 / j$. aprim.2014.09.004.

19. Friedewald Equation for Low Density Lipoprotein (LDL-C). Available from: https://www.merckmanuals. com/medical-calculators/Friedewald.htm.

20. American Diabetes Association. 2. Classification and Diagnosis of Diabetes: Standards of Medical Care in Diabetes - 2019. Diabetes Care. 2019;42 (Supplement 1):13-28. DOI: $10.2337 / \mathrm{dc} 19-\mathrm{S} 002$.

21. Alberti KGMM, Eckel RH, Grundy SM, Zimmet PZ, Cleeman JI, Donato KA, et al. Harmonising the metabolic syndrome: A joint interim statement of the International Diabetes Federation Task Force on Epidemiology and Prevention; National Heart, Lung, and Blood Institute; American Heart Association; World HeartFederation; International Atherosclerosis Society; and International Association for the Study of Obesity. Circulation. 2009;120(16):1640-1645. DOI: 10.1161/CIRCULATIONAHA.109.192644. 
22. Bermúdez V, Rojas J, Salazar J, Calvo MJ, Morillo J, Torres W, et al. The Maracaibo city metabolic syndrome prevalence study: primary results and agreement level of 3 diagnostic criteria. Latinoam Hipertens. 2014;9(4):20-32. http://190.169.30.98/ ojs/index.php/rev_lh/article/view/9730.

23. Stepenka V, Rivas Y, Zapata Y, Añez L, Casal J, Sindas M, et al. Prevalencia de Prediabetes y Diabetes Mellitus en la región de Zulia, Venezuela. Resultados Preliminares del Estudio EVESCAM. Med Interna. 2018;34(3):179-183. https://www.svmi.web.ve/ojs/ index.php/medint/article/view/483.

24. Booth FW, Roberts CK, Laye MJ. Lack of exercise is a major cause of chronic diseases. Compr Physiol. 2012;2(2):1143-1211. DOI: 10.1002/cphy.c110025.

25. Werneck AO, Baldew S-S, Miranda JJ, Díaz Arnesto O, Stubbs B, Silva DR, et al. Physical activity and sedentary behavior patterns and socio-demographic correlates in 116982 adults from six South American countries: The South American physical activity and sedentary behavior network (SAPASEN). Int J Behav Nutr Phys Act. 2019;16(1):68. DOI: 10.1186/s12966019-0839-9.

26. Luis de Moraes Ferrari G, Kovalskys I, Fisberg M, Gómez G, Rigotti A, Sanabria LYC, et al. Original research Socio-demographic patterning of selfreported physical activity and sitting time in Latin American countries: Findings from ELANS. BMC Public Health. 2019;19(1):1723. DOI: 10.1186/ s12889-019-8048-7.

27. Lopez R, Hurtado D, Gómez LL, Martínez JA, Chazzin $\mathrm{G}$, Castillo E, et al. Una aproximación a conocer la prevalencia de hipertensión arterial, factores de riesgo cardiovascular y estilo de vida en Venezuela. Avances Cardiol. 2014;34(2):128-134. http://cania.msinfo. info/bases/biblo/texto/pdf2/ lopeznouel.pdf.

28. Te Velde SJ, Haraldsen E, Vik FN, De Bourdeaudhuij I, Jan N, Kovacs E, et al. Associations of commuting to school and work with demographic variables and with weight status in eight European countries: The ENERGY-cross sectional study. Prev Med. 2017;99:305-312. DOI: 10.1016/j. ypmed.2017.03.005.

29. Gell NM, Wadsworth DD. How do they do it: Working women meeting physical activity recommendations. Am J Health Behav. 2014;38(2):208-217. DOI: 10.5993/ajhb.38.2.6.

30. Meseguer CM, Galán I, Herruzo R, Zorrilla B, Rodríguez-Artalejo F. Leisure-Time Physical Activity in a Southern European Mediterranean Country: Adherence to Recommendations and Determining Factors. Rev Esp Cardiol. 2009;62(10):1125-1133. DOI: $10.1016 / \mathrm{s} 1885-5857(09) 73327-4$.

31. Florindo AA, Guimarães VV, Cesar CLG, Barros MB de A, Alves MCGP, Goldbaum M. Epidemiology of leisure, transportation, workal, and household physical activity: prevalence and associated factors. J Phys Act Health. 2009;6(5):625-632. DOI: 10.1123/ jpah.6.5.625.

32. Gerike R, Nazelle A, Nieuwenhuijsen M, Int Panis L, Anaya Boig E, Avila-Palencia I, et al. Physical Activity through Sustainable Transport Approaches (PASTA): A study protocol for a multicentre project. BMJ Open. 2016;6:e009924. DOI: 10.1136/ bmjopen-2015-009924.

33. Medina C, Janssen I, Barquera S, Bautista-Arredondo S, González ME, González C. Workal and leisure time physical inactivity and the risk of type II diabetes and hypertension among Mexican adults: A prospective cohort study. Sci Rep. 2018;8(1):5399. DOI: 10.1038/ s41598-018-23553-6.

34. Díaz-Martínez X, Petermann F, Leiva AM, Garrido-Méndez A, Salas-Bravo C, Martínez MA, et al. Association of physical inactivity with obesity, diabetes, hypertension and metabolic syndrome in the chilean population. Rev Med Chil. 2018;146(5):585-595. DOI: http://dx.doi.org/10.4067/ s0034-98872018000500585. 